\title{
Historia clínica: Documento médico legal en odontología
} Clinical History: Legal medical document in odontology

\author{
Ana J. Monjarás-Ávila ${ }^{a}$, Juan R. de Santiago-Tovar ${ }^{b}$, Ana K. Bazán-Suárez ${ }^{c}$, Zaida K. \\ Pacheco-Martínez ${ }^{d}$, Carmen Balderas-Delgadillo ${ }^{e}$.
}

\begin{abstract}
The patient's medical history is of great importance before starting any dental procedure and should be considered as an obligation, since it is a legal medical document that meets the requirements established in federal and state laws and regulations to define part of the In addition, the information provided by the patient is considered to be the first step in any planning and basis of the correct diagnosis for decision making in the design of the treatment plan. Studies have shown that, with a careful clinical history of the patient, $90 \%$ of risk situations can be avoided.
\end{abstract}

\section{Key Words}

Anamnesis, ASA, health, disease

\section{Resumen}

La historia clínica de los pacientes es de gran importancia antes de iniciar cualquier procedimiento odontológico y debe ser considerado como una obligación, ya que es un documento médico legal que cumple con los requisitos establecidos en las leyes y reglamentos federales y estatales para definir parte de la información de salud de un individuo, además, los datos brindados por el paciente se consideran el primer paso en cualquier planificación y base del diagnóstico correcto para la toma de decisiones en el diseño del plan tratamiento. Los estudios han demostrado que, con un historial clínico cuidadoso del paciente, el $90 \%$ de situaciones de riesgo se pueden evitar.

\section{Palabras clave}

Anamnesis, ASA, salud, enfermedad

\section{Introducción}

La Academia Americana de Medicina Oral (AAOM) afirma que comprender la salud de los pacientes es importante para la atención dental adecuada y la salud general del paciente.

El historial médico debe ser una evaluación exhaustiva $y$ precisa de las afecciones $y$ enfermedades sistémicas, que se derivan de la información proporcionada por el paciente o tutor del mismo, en el caso de un menor de edad o cuando el individuo no se encuentre en la facultad física y/o psicológica para responder, y se puede obtener de manera escrita en un formulario estandarizado o electrónico, reflejando con precisión el estado de salud general pasado y actual.

a Autor de correspondencia, Universidad Autónoma del Estado de Hidalgo, Instituto de Ciencias de la Salud, ORCID:/0000-0002-5916-6510, Email: ana_monjaras@uaeh.edu.mx b Universidad Autónoma del Estado de Hidalgo, Instituto de Ciencias de la Salud, Email: juandesantiago@uaeh.edu.mx 
La información recabada es importante para comprender las posibles relaciones entre el impacto de la salud sistémica, los medicamentos y las intervenciones terapéuticas en la salud orofacial del paciente y su capacidad para tolerar el tratamiento dental.

Las principales secciones de la historia clínica están bien establecidas. Es importante que los practicantes sigan un esquema sistemático de consulta para minimizar la falta de información importante. Es así como, este diagrama puede servir de referencia rápida y útil con recomendaciones que proporcionan orientación sobre la recopilación de la historia médica y dental del paciente, alentando al odontólogo a obtener un historial clínico preciso y completo de todos los pacientes En la práctica odontológica la revisión de sistemas del cuerpo humano se lleva a cabo principalmente para resaltar las condiciones relevantes que pudieran poner en riesgo la salud del paciente durante su tratamiento odontológico y así modificar las especificaciones terapéuticas previas a este, así como prever las circunstancias en las que el pronóstico de su tratamiento pudiera verse afectado, como las que veremos a continuación.

\section{Sistema cardiovascular}

La mayoría de los odontólogos se protege prescribiendo antibiótico en todo paciente con algún problema cardiaco, sin embargo, esto podría exponer al paciente a una resistencia bacteriana por su uso indiscriminado, desconociendo que en casos como, defecto estructural cardiaco o algún reemplazo valvular no está indicado.

Se debe aplazar cualquier tratamiento dental durante tres meses en pacientes que tuvieron un infarto al miocardio, y está contraindicada la anestesia general durante los primeros 6 meses posteriores a este episodio.

El odontólogo debe estar preparado con medicamentos de emergencia y oxigeno ante cualquier paciente con angina de pecho y debe indagar en el interrogatorio a profundidad sobre la frecuencia de los ataques.

Se verificará la toma de presión arterial de pacientes hipertensos para determinar su control y el tipo de anestésico que se usará en el procedimiento, si el paciente presenta más de $160 / 100 \mathrm{mmHg}$ se deberá posponer el tratamiento quirúrgico hasta obtener un mejor control.

\section{Sistema respiratorio}

Todo paciente con dificultad para respirar y presencia de tos se debe tomar en cuenta en la historia clínica para comenzar a tratar ya que podrían dificultar el tratamiento.

\section{Sistema gastrointestinal}

El sistema gastrointestinal es la continuación del sistema estomatognático, por lo que se tomará en cuenta con gran importancia, ya que este nos puede proporcionar datos importantes de hábitos que están afectando la cavidad bucal, así como modificar nuestra prescripción médica en caso de ulceras gástricas, habrá que poner especial atención en síntomas como disfagia(dificultad para tragar), odinofagia(dolor al tragar), indigestión, nausea o vomito, hematemesis (vómito de sangre), ya que se podría tratar de un esquema más severo o cáncer que pudiéramos remitir con el especialista adecuado.

\section{Enfermedades del hígado}

Las enfermedades del hígado son un foco rojo en nuestra historia médica odontológica, ya que estos pacientes pueden llegar a presentar problemas de sangrado, riesgo de infección por varios tipos de virus de la hepatitis, algunas veces se encuentra afectada la coagulación por una inadecuada función hepática, por lo que se deberá pedir un conteo sanguíneo completo y tener especial atención con los medicamentos recetado, si se requiere de sedación se llevará a cabo con mucha precaución. 


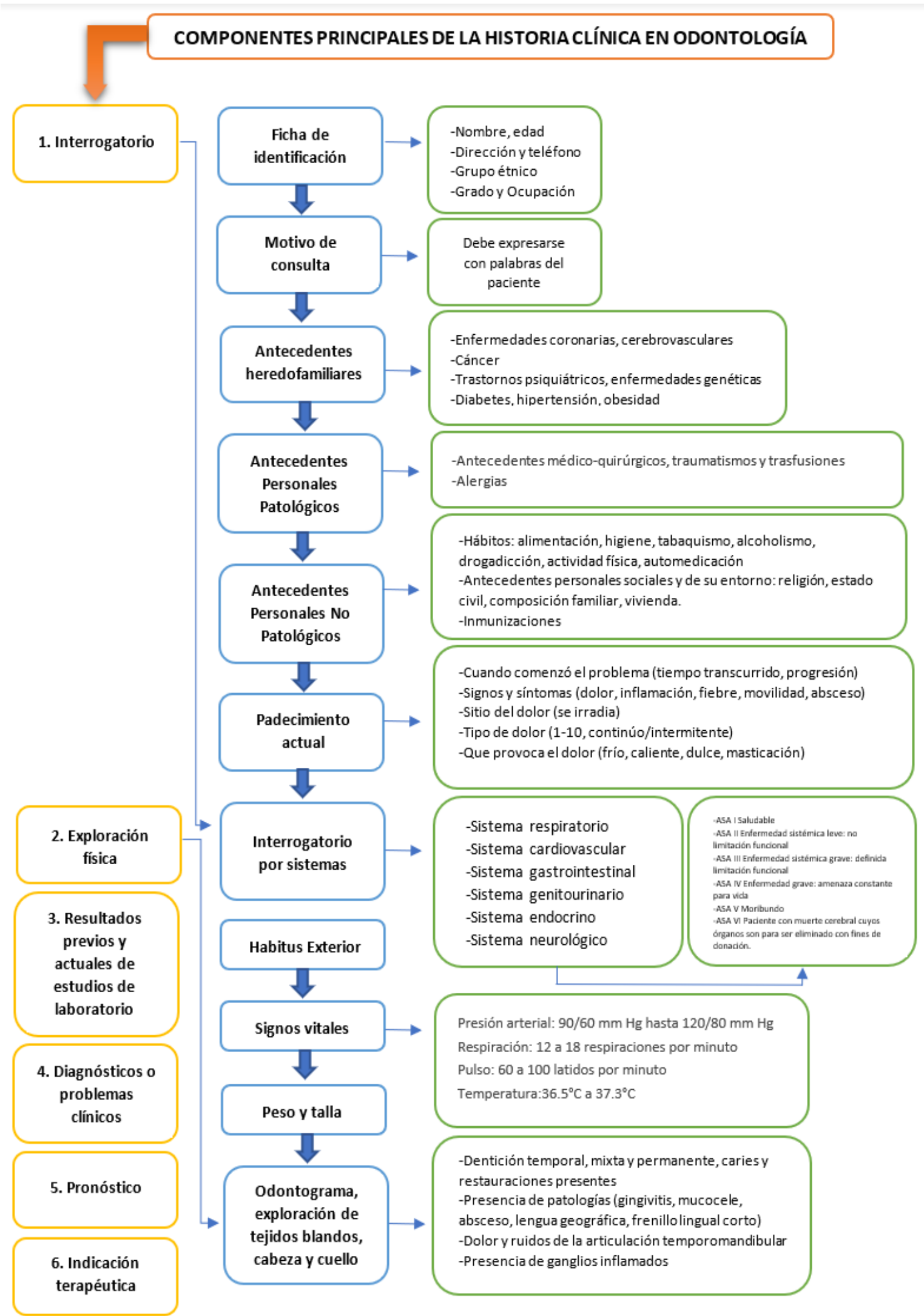




\section{Sistema neurológico}

En pacientes bajo tratamiento neurológico se tomará en cuenta cualquier historial de ataques y desmayos, así como dolor de cabeza y dolor facial, el cual se puede confundir con el motivo de consulta dental del paciente, que se deberá descartar bajo criterios específicos de diagnóstico odontológico, la función motora también se puede ver afectada, lo que implica una mala higiene oral del paciente.

\section{Epilepsia}

En pacientes con epilepsia se debe investigar sobre la naturaleza de las convulsiones y su control, haciendo principal hincapié sobre los cambios recientes en la medicación y el conocimiento de los tres últimos episodios.

\section{Enfermedad renal}

Los pacientes de diálisis renal se tratan mejor el día después de la diálisis cuando la función renal es óptima y el efecto de la heparina ha desaparecido. Se deberá vigilar cualquier infección oral debido a su estado inmunodeprimido, tomando en cuenta los medicamentos contraindicados para ser utilizados con precaución en estos pacientes.

El odontólogo debe ser consciente de que el paciente no siempre proporciona toda la información y debido a esto el historial médico a menudo suele estar incompleto, por lo tanto, el método de diálogo con el paciente debe utilizarse para confirmar su precisión, además de estrechar un vínculo con este, por lo que el al finalizar el interrogatorio y exploración exhaustiva, el paciente debe firmar para testificar la información proporcionada.

La historia clínica es parte del expediente clínico, que es un instrumento de gran relevancia para la protección de la salud y los datos personales, los cuales deben ser manejados con discrecionalidad y confidencialidad por parte del personal médico y en general, tomándose en cuenta que la información del paciente a tratar pudiendo llevar a revelaciones importantes, como es en el caso de enfermedades genéticas o hereditarias, debido a esto se debe cumplir con los principios científicos y éticos de la práctica médica.

Anteriormente en la Norma Oficial Mexicana NOM004SSA3-2012 sobre expediente clínico, se establecía que sólo las autoridades judiciales eran las únicas competentes para solicitar los expedientes clínicos, y el paciente sólo podía obtener información en forma verbal de este, posteriormente se determinó que el paciente tiene derecho a la expedición de una copia íntegra de su expediente clínico, pues en éste, se contiene la información necesaria para que se tenga pleno conocimiento de su estado de salud y, por ende, no debe existir condicionante alguna para su emisión, mientras sean titulares de los datos 0 a sus representantes legales.

Por último, conviene enfatizar en la necesidad de contar con normatividad interna en cada institución que permita definir el acceso, uso y alcance de los datos de salud, tomando en cuenta los perfiles y fines que persigan ya sea de investigación o académicos, sin dejar al lado el fin de construir una cultura entre los profesionales de la salud sobre este derecho de los pacientes.

\section{Conclusión:}

La historia clínica, es el documento médico legal más utilizado, debido a que permite valorar al paciente en estado actual, para poder hacer un diagnóstico y poder llevar a cabo la continuidad del tratamiento del paciente.

La historia clínica deberá hacerse respetando cada uno de los componentes principales para poder prevenir y saber cómo actuar ante cualquier situación de riesgo.

\section{Referencias}

[1] DOF - Diario Oficial de la Federación. (n.d.). Retrieved August 25, 2019, from http://dof.gob.mx/nota_detalle.php?codigo $=527278$ $7 \&$ fecha $=15 / 10 / 2012$

[2] Clinical Practice Statement: Medical History. (n.d.). Retrieved August 25, 2019, from https://www.aaom.com/index.php?option=com_con tent $\&$ view $=$ article $\& i d=108$ :medicalhistory\&catid=24:clinical-practice-statement

[3] Kurczyn Villalobos, P. (2019). Contenido e importancia del expediente clínico. Acceso y confidencialidad. Revista de La Facultad de Derecho de México, 69(273-2), 893. https://doi.org/10.22201/fder.24488933e.2019.2732.68634 
[4] Arellano-Mejía, J., \& Sánchez-Morales, C. A. (2017). ¿El expediente clínico debe ser clasificado como confidencial y reservado? Revista Del Instituto Nacional de Enfermedades Respiratorias, 76(2), 111-122.

[5] Mortazavi, H., Rahmani, A., \& Rahmani, S. (n.d.). Summer 2015; 287-290 All Rights Reserved for Official Publication of. In International Journal of Medical Reviews Review Article International Journal of Medical Reviews (Vol. 2).

[6] Hussain, M. (2015). Essentials of medical historytaking in dental patients. Dental Update, 42(7), 687. https://doi.org/10.12968/denu.2015.42.7.687

[8] González Rodríguez, R., \& Juan Cardentey García, I. (n.d.). La historia clínica médica como documento médico legal The clinical medical record as a legal medical document.

[9] Legal Medical Record Standards. (n.d.). 